\title{
Abdominal Obesity in German Adolescents Defined by Waist-to-Height Ratio and Its Association to Elevated Blood Pressure: The KigGS Study
}

\author{
Katrin Kromeyer-Hauschild ${ }^{a}$ Hannelore Neuhauser $^{b}$ \\ Angelika Schaffrath Rosario $^{\mathrm{b}}$ Anja Schienkiewitz ${ }^{\mathrm{b}}$ \\ ${ }^{a}$ Institute of Human Genetics, Jena University Hospital, Friedrich Schiller University, Jena, \\ ${ }^{b}$ Department of Epidemiology and Health Reporting, Robert Koch Institute, Berlin, Germany
}

\section{Key Words}

Body mass index $\cdot$ Waist-to-height ratio $\cdot$ Abdominal obesity $\cdot$ Blood pressure $\cdot$ Adolescents

\begin{abstract}
Objective: The aim of this study was to compare the fixed 0.5 cut-off and the age- and sexspecific 90th percentile (P90) for waist-to-height ratio (WHtR) in German adolescents with respect to the prevalence of abdominal obesity and to compare the screening ability of WHtR and BMI to identify hypertensive blood pressure (BP) values. Methods: Between 2003 and 2006, the German Health Interview and Examination Survey for Children and Adolescents (KiGGS) was carried out including 3,492 boys and 3,321 girls aged 11-17 years. Abdominal obesity was assessed by two WHtR cut-points (P90; 0.5). Hypertensive BP was defined as BP exceeding age-, sex- and height-specific 95th percentiles or the adult threshold for hypertension (140/90 mm Hg). Results: Agreement between the WHtR cut-offs was very good (Kappa 0.89 for boys; 0.81 for girls), and the prevalence of abdominal obesity was slightly higher using P90 (boys 12.0\%; girls 11.3\%) compared to 0.5 (boys 10.7\%; girls $8.0 \%$ ). WHtR and BMIfor-age had equivalent ability to discriminate hypertensive BP (ROC-AUC $<0.7$; sensitivity of the 0.5 cut-off for detecting hypertensive BP < 30\%). Conclusion: The fixed $0.5 \mathrm{WHtR}$ cut-off can be used in German adolescents to characterize abdominal obesity. However, WHtR is not suitable as a screening tool for hypertensive BP in adolescents.
\end{abstract}


Kromeyer-Hauschild et al.: Abdominal Obesity in German Adolescents Defined by Waist-to-Height Ratio and Its Association to Elevated Blood Pressure: The KiGGS Study

\section{Introduction}

In times of high obesity prevalences, efficient diagnostic tools to identify children and adolescents with unfavorable health risks become more important. In a recent meta-analysis, the waist-to-height ratio (WHtR) has been shown to have higher screening potential for adult cardiometabolic risk than waist circumference [1]. WHtR is receiving increasing attention as a measure of abdominal obesity in children and adolescents that is linked to obesity-related cardiovascular risk in adulthood $[2,3]$. Because WHtR is only weakly associated with age, it has been suggested that the same cut-off value of 0.5 could be used across all age groups in children and adolescents $[4,5]$. The advantage is that population-specific reference tables as well as ageand sex-specific cut-off values are not required, in contrast to obesity definitions based on BMI which are highly age-dependent. The WHtR cut-off of 0.5 was established based on studies in adults that investigated the associations between WHtR and metabolic syndrome and cardiovascular comorbidities $[1,6,7]$. Although a growing number of studies have supported the use of this cut-off in children and adolescents, a systematic review on WHtR with a cut-off of 0.5 highlighted the need for further studies in children [8]. Some studies indicate that the cut-point of WHtR of 0.5 is not ideal for all ages $[9,10]$, suggesting the need for age-related references. Moreover, there are only a few studies which investigated the sensitivity of this cut-off point to identify obesity or risk of cardiovascular disease (CVD) in children and adolescents [11,12].

The objective of this current study was to compare the fixed 0.5 cut-off and the age- and sex-specific 90th percentile (P90) for WHtR in a representative sample of adolescents from Germany with respect to the prevalence of abdominal obesity and to compare the screening ability of WHtR and BMI to identify hypertensive blood pressure (BP) values.

\section{Subjects and Methods}

\section{Subjects and Measurements}

Data from the German Health Interview and Examination Survey for Children and Adolescents (KiGGS) were used in the analysis. This population-based, nationally representative, cross-sectional health examination survey was carried out from May 2003 to May 2006 with 17,641 participants (8,985 boys, 8,656 girls) aged 0-17 years living in Germany (response rate 67\%). The study design and procedures have been described in detail elsewhere [13]. The current analyses are based on 6,813 subjects $(3,492$ boys, 3,321 girls $)$ aged 11-17 years, of which 6,709 subjects (3,440 boys and 3,269 girls) had complete data sets.

The Federal Office for Data Protection and the 'Charité Universitätsmedizin Berlin' ethics committee approved the survey. Written informed consent was obtained from all parents or caregivers as well as from participants aged 14 years or older.

Anthropometric measurements were performed by trained staff as described previously [14] according to standardized guidelines [15]. In brief, height was measured to the nearest $0.1 \mathrm{~cm}$ with a portable Harpenden stadiometer (Holtain Ltd., Crymych, UK) and body weight to the nearest $0.1 \mathrm{~kg}$ using a calibrated electronic scale (SECA, Birmingham, UK). A non-elastic tape was used to measure waist circumference (WC) at the level of the natural waist, which is the narrowest part of the torso, as seen from the anterior aspect, to the nearest $0.1 \mathrm{~cm}$. For each subject BMI was calculated as weight divided by height squared $\left(\mathrm{kg} / \mathrm{m}^{2}\right)$ and WHtR as WC divided by height.

Systolic and diastolic BP were measured with an automated oscillometric device (Datascope Accutorr Plus; SOMA Technology, Inc., Bloomfield CT, USA) according to a standardized protocol [16]. Two measurements were taken at a 2-min interval on the right arm in the sitting position, elbow at the level of the right atrium and using one of 4 cuff sizes. The average of the two measurements was used for analyses.

\section{Classification of the Subjects}

For the analyses, subjects were classified according to BMI and WHtR.

To classify the subjects as overweight and obese, the international BMI-based classification system recommended by the IOTF [17] was used. In this system, the age- and sex-specific BMI cut-offs that corre- 
Kromeyer-Hauschild et al.: Abdominal Obesity in German Adolescents Defined by

spond to a BMI of $25 \mathrm{~kg} / \mathrm{m}^{2}$ or $30 \mathrm{~kg} / \mathrm{m}^{2}$ at age 18 were used to identify subjects as overweight or obese, respectively.

To assess abdominal obesity, the cut-off of 0.5 [5] was used and compared to the age- and sex-related P90 for WHtR that have been reported previously from the KiGGS study [16]. These percentiles were calculated using the LMS method [18]. Participants with incomplete or invalid measurements as well as participants with chronic conditions or intake of medication that can influence growth and weight development had been excluded from the reference population.

BP was classified as hypertensive when the systolic and/or diastolic BP was at or above the 95th age-, sex- and height-specific percentile according to the KiGGS reference data or if the adult threshold for hypertension of 140/90 $\mathrm{mm} \mathrm{Hg}$ was exceeded $[19,20]$.

\section{Statistical Analysis}

Statistical analyses were performed using SPSS for Windows (version 19.0; SPSS Inc, Chicago, IL, USA) and SAS (version 9.2; Cary, NC, USA). A level p < 0.05 was used to indicate statistical significance.

Sampling weights [13] were used in all analyses to account for unequal sampling probabilities and to reflect the distribution of the population (on December 31, 2004) with respect to age, sex, living in Eastversus West-Germany versus Berlin and German/non-German nationality. In the calculation of $p$ values and confidence intervals, the sampling design and weighting were accounted for by using the survey procedures in SAS indicating the study location as cluster variable.

To adjust BMI and WHtR for age, Z-scores were calculated using the LMS values presented for reference data from KiGGS $[16,21,22]$. The calculated Z-scores are termed here 'BMI-for-age' and 'WHtR-for-age'. BP was adjusted for age, sex and height using KiGGS reference data [20].

After cross-classification of the WHtR in categories according to the two cut-off points $(</ \geq 0.5$ and $</ \geq$ P90), Cohen's kappa was calculated to measure the agreement between the two methods. A kappa of 0.0 is interpreted as evidence that the agreement is no better than chance alone, while a kappa between 0.81 and 1.00 demonstrates very good agreement. Values of $0.20,0.21-0.40,0.41-0.60$, and $0.61-0.80$ are interpreted as showing poor, fair, moderate and good agreement, respectively [23].

The associations between BMI-for-age, WHtR and WHtR-for-age as well as between age-adjusted systolic and diastolic BP and WHtR were tested by means of Pearson correlation coefficients.

The ability of BMI-for-age, WHtR, and WHtR-for-age to predict hypertensive BP values was also assessed by receiver operating characteristics (ROC) to determine the area under the curve (AUC). To evaluate the ability of the two cut-offs ( 0.5 and P90) of WHtR to detect hypertensive BP values, sensitivity, specificity as well as positive and negative predictive values were calculated. This analysis was also performed for obesity based on IOTF criteria [17]. In addition, ROC analysis by sex was carried out to find the WHtR cut-offs with the best trade-off between sensitivity and specificity to identify subjects with hypertensive BP values. This is the point on the AUC which maximizes the sum of sensitivity and specificity. For these cut-offs, the sensitivity, specificity as well as positive and negative predictive values were calculated.

\section{Results}

Characteristics of the study participants are shown in table 1 . The median value for BMI was significantly lower for boys than for girls, whereas the medians of waist, WHtR, systolic and diastolic BP were all significantly higher among male subjects. The prevalence rates of hypertensive BP and overweight were also significantly higher in boys than in girls while the prevalence rates for obesity were only non-significantly higher in boys. In the group of overweight adolescents, $45.5 \%$ of boys and $37.4 \%$ of girls had abdominal obesity with a WHtR $\geq$ 0.5 . In obese subjects, this was the case for most adolescents ( $92.3 \%$ of boys, $87.1 \%$ of girls), whereas in the non-overweight group only $0.3 \%$ were found with a high WHtR.

Figure 1 illustrates the age-dependent changes in WHtR in both sexes. In boys, the WHtR decreased slightly up to the age of 15 years and increased slightly thereafter, whereas the WHtR remained nearly constant across the age range in girls. In both sexes, the P90 was slightly below the recommended cut-off of 0.5 for WHtR (except for boys aged 11-12.5 years, where P90 was slightly higher than 0.5 ). This good agreement was confirmed after cross- 
Kromeyer-Hauschild et al:: Abdominal Obesity in German Adolescents Defined by

Table 1. Characteristics of the study population $(n=6,813)$

\begin{tabular}{|c|c|c|c|}
\hline & Boys $\left(n=3,492^{c}\right)$ & Girls $\left(n=3,321^{c}\right)$ & p value ${ }^{d}$ \\
\hline \multicolumn{4}{|l|}{ Age, years } \\
\hline $11-13$ & 1,588 & 1,488 & \\
\hline \multirow[t]{3}{*}{$14-17$} & 1,904 & 1,833 & \\
\hline & \multicolumn{2}{|l|}{ Mean (SD) } & \\
\hline & boys & girls & \\
\hline \multirow[t]{3}{*}{ Height, cm } & $167.7(13.7)$ & $161.6(8.8)$ & $<0.001$ \\
\hline & \multicolumn{2}{|c|}{ Median (25th, 75th percentile) } & \\
\hline & boys & girls & \\
\hline Weight, kg & $59.3(47.6,69.5)$ & $54.6(48.0,62.3)$ & $<0.001$ \\
\hline BMI, $\mathrm{kg} / \mathrm{m}^{2}$ & $20.3(18.2,22.8)$ & $20.6(18.6,23.0)$ & 0.001 \\
\hline $\mathrm{WC}, \mathrm{cm}$ & $71.3(66.1,77.3)$ & $67.3(63.4,72.4)$ & $<0.001$ \\
\hline WHtR & $0.42(0.40,0.46)$ & $0.41(0.39,0.45)$ & $<0.001$ \\
\hline Systolic BP, mm Hg & $116(108,124)$ & $112(106,118)$ & $<0.001$ \\
\hline \multirow[t]{3}{*}{ Diastolic BP, mm Hg } & $68(63,73)$ & $68(63,72)$ & $<0.001$ \\
\hline & \multicolumn{2}{|l|}{$\%(95 \% \mathrm{Cl})$} & \\
\hline & boys & girls & \\
\hline Hypertensive $\mathrm{BP}^{\mathrm{a}}$ & $11.3(10.0-12.9)$ & $9.7(8.4-11.2)$ & 0.04 \\
\hline Overweight $t^{b}$ & $22.9(21.3-24.5)$ & $20.6(19.0-22.2)$ & 0.04 \\
\hline Of these WHtR $\geq 0.5$ & 45.5 (41.5-49.5) & $37.4(33.1-41.9)$ & 0.003 \\
\hline Obesity ${ }^{\mathrm{b}}$ & $6.1(5.3-7.1)$ & $5.3(4.5-6.2)$ & 0.13 \\
\hline Of these WHtR $\geq 0.5$ & $92.3(86.8-95.6)$ & $87.1(80.5-91.7)$ & 0.12 \\
\hline
\end{tabular}

$\mathrm{CI}=$ Confidence limits.

${ }^{a}$ Hypertensive blood pressure defined as systolic and/or diastolic BP $\geq 95$ th age-, sex- and height-specific percentile according to the KiGGS references or if adult threshold $\geq 140 / 90 \mathrm{~mm} \mathrm{Hg}$.

${ }^{b}$ Overweight and obesity according to BMI using the IOTF definition; overweight includes obesity.

${ }^{c} n=52$ boys and $n=47$ girls with missing BP values.

${ }^{\mathrm{d}}$ Tests for sex differences ( $\mathrm{t}$-test for height and age, Mann Whitney U-test for weight, WC, BMI, WHtR, systolic and diastolic BP, $\chi^{2}$-test for overweight and obesity).

classification of the WHtR into categories according to both the constant cut-off of 0.5 and P90 and calculating Cohen's kappa which was 0.892 for boys and 0.808 for girls. $97.2 \%$ of the subjects were classified concordantly, i.e. $9.1 \%$ with abdominal obesity according to both cut-offs (WHtR $\geq 0.5$ and $\geq$ P90) and $88.1 \%$ with a WHtR less than 0.5 as well as less than P90. Of the $2.7 \%$ subjects classified in discordant categories, the majority (2.5\%) had a WHtR $\geq$ P90 but $<0.5$. Based on the constant WHtR cut-off of $0.5,10.7 \%$ of the boys and $8.0 \%$ of the girls had abdominal obesity (table 2). While in boys higher prevalence rates were found in the younger age group, there were no age differences in girls. According to the percentilebased definition, $12.0 \%$ of the boys and $11.3 \%$ of the girls had abdominal obesity, with no statistically significant age or sex differences. Compared to the prevalence rates based on the constant cut-off, the percentile-based prevalence rates were $1.3 \%$ higher in male and $3.3 \%$ higher in female subjects. 
Table 2. Prevalence of abdominal obesity in German adolescents defined by different WHtR cut-offs
Kromeyer-Hauschild et al.: Abdominal Obesity in German Adolescents Defined by Waist-to-Height Ratio and Its Association to Elevated Blood Pressure: The KiGGS Study

\begin{tabular}{|c|c|c|}
\hline Age, years & $\begin{array}{l}\text { WHtR } \geq 0.5 \\
\%(95 \% \mathrm{CI})\end{array}$ & $\begin{array}{l}\text { WHtR } \geq \text { P90, } \\
\%(95 \% \mathrm{CI})\end{array}$ \\
\hline \multicolumn{3}{|l|}{ Boys } \\
\hline $11-13(n=1,567)$ & $12.4(10.6-14.5)^{* \S}$ & $12.1(10.3-14.1)$ \\
\hline $14-17(n=1,885)$ & $9.5(8.2-11.1)^{*}$ & $11.9(10.4-13.6)$ \\
\hline Total & $10.7(9.5-11.9)^{\S}$ & $12.0(10.8-13.3)$ \\
\hline \multicolumn{3}{|l|}{ Girls } \\
\hline $11-13(n=1,476)$ & $7.9(6.3-9.8)^{\S}$ & $11.1(9.3-13.2)$ \\
\hline $14-17(\mathrm{n}=1,813)$ & $8.0(6.7-9.6)$ & 11.4 (9.9-13.2) \\
\hline Total & $8.0\left(6.9-9 . .^{2}\right) \S$ & $11.3(10.1-12.6)$ \\
\hline
\end{tabular}

*Significant differences between age groups.

${ }^{\S}$ Significant differences between sexes $\left(\chi^{2}\right.$ test; $\left.\mathrm{p}<0.05\right)$.

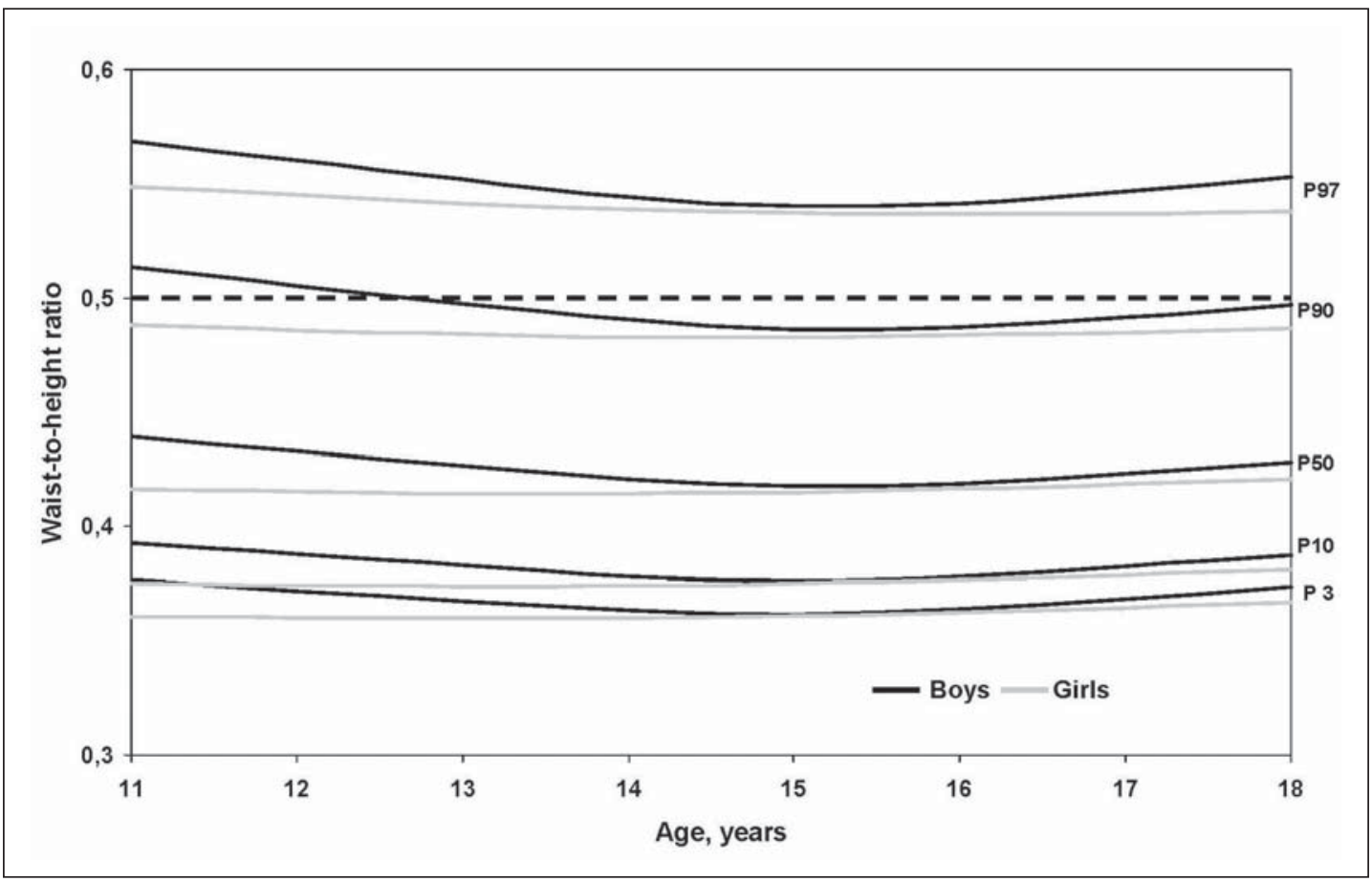

Fig. 1. Percentile curves of WtHR for German adolescents aged 11-17 years. Dashed line superimposes the cut-off of 0.5 .

There was a strong positive and significant correlation between WHtR or WHtR-for-age and BMI-for-age ( $r=0.852$, for both sexes or $r=0.860$ and 0.855 in boys and girls, respectively; $\mathrm{p}<0.001$ ), indicating that subjects with high BMI had a high WHtR.

The association measures between anthropometric indices and BP values indicate a moderate positive correlation in both sexes between WHtR-for-age and age-, sex- and heightadjusted systolic and diastolic BP (Z-scores) (systolic BP r $=0.296$ and 0.183 , diastolic BP $r=$ 0.141 and 0.065 in boys and girls, respectively; $p<0.001$ ). The use of unadjusted measures of WHtR yielded almost identical results (systolic BP $r=0.290$ and 0.182 , diastolic BP $r=$ 
Kromeyer-Hauschild et al.: Abdominal Obesity in German Adolescents Defined by

Table 3. Area under ROC curve of BMI-for-age, WHtR-for-age and WHtR for identifying hypertensive BP in both sexes

\begin{tabular}{|c|c|c|c|c|c|}
\hline \multirow[t]{2}{*}{ Risk factor } & \multirow[t]{2}{*}{ Measure } & \multicolumn{2}{|l|}{ Boys } & \multicolumn{2}{|l|}{ Girls } \\
\hline & & AUC & $95 \% \mathrm{CI}$ & AUC & $95 \% \mathrm{CI}$ \\
\hline \multicolumn{6}{|c|}{ Systolic BP $\geq$ P95 } \\
\hline & BMI-for-age (Z-score) & 0.720 & $0.689-0.751$ & 0.655 & $0.618-0.693$ \\
\hline & WHtR-for-age & 0.697 & $0.665-0.728$ & 0.646 & $0.607-0.686$ \\
\hline & WHtR & 0.692 & $0.660-0.724$ & 0.648 & $0.608-0.687$ \\
\hline \multicolumn{6}{|c|}{ Diastolic BP $\geq$ P95 } \\
\hline & BMI-for age (Z-score) & 0.613 & $0.572-0.654$ & 0.557 & $0.512-0.601$ \\
\hline & WHtR-for-age & 0.606 & $0.564-0.648$ & 0.566 & $0.522-0.610$ \\
\hline & WHtR & 0.604 & $0.562-0.646$ & 0.567 & $0.523-0.611$ \\
\hline \multicolumn{6}{|c|}{ Hypertensive BP\# } \\
\hline & BMI-for age (Z-score) & 0.684 & $0.655-0.712$ & 0.607 & $0.574-0.641$ \\
\hline & WHtR-for-age & 0.667 & $0.638-0.695$ & 0.604 & $0.570-0.638$ \\
\hline & WHtR & 0.664 & $0.635-0.692$ & 0.605 & $0.571-0.639$ \\
\hline
\end{tabular}

P95 = 95th percentile.

\#Systolic and/or diastolic BP $\geq 95$ th percentile or $\geq$ the adult threshold for hypertension of 140/90 mm Hg.

Table 4. Classification of hypertensive BP values by BMI-based obesity and high WHtR in both sexes

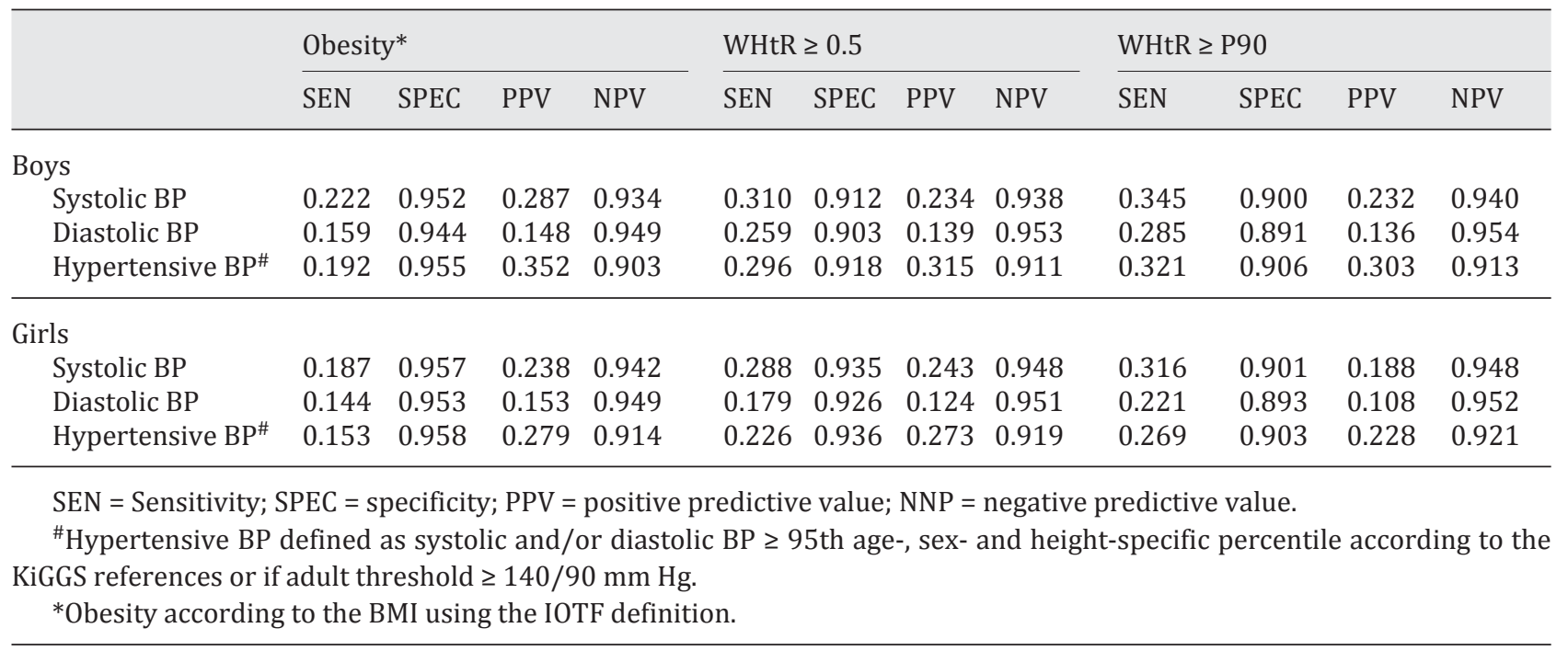

0.138 and 0.065 in boys and girls, respectively; $p<0.001$ ). BMI-for-age showed slightly higher correlations with both systolic and diastolic BP Z-scores (systolic BP $r=0.343$ and $r=0.210$, diastolic BP $r=0.160$ and 0.073 in boys and girls, respectively; $p<0.001$ ) compared to WHtRfor-age and WHtR.

Table 3 shows that WHtR, WHtR-for-age and BMI-for-age had a nearly identical but overall modest ability to identify children with hypertensive BP values, with AUC values ranging from 0.56 to 0.72 . The use of either adjusted or unadjusted measures of WHtR yielded almost identical results. All parameters had rather low sensitivities and positive predictive 
values at the given cut-off points (table 4). The ability of the WHtR cut-off 0.5 to identify the $10.5 \%$ adolescents with hypertensive BP values was low: only a quarter of adolescents with hypertensive BP were identified, but the majority (3/4) could not be identified by this WHtR cut-off (data in detail not shown).

In contrast, the specificities and negative predictive values were high (table 4). BMI-forage had a somewhat higher specificity but a lower sensitivity than WHtR. The constant cut-off of 0.5 revealed slightly lower sensitivities but higher specificities and positive predictive value than the cut-off of P90. The negative predictive values were almost identical between both cut-offs. WHtR cut-offs with the best trade-off between sensitivity and specificity to identify subjects with hypertensive BP values were 0.43 in boys and 0.42 in girls. These cut-offs showed a higher but also only moderate sensitivity ( 0.617 in boys, 0.567 in girls). The specificity ( 0.596 in boys and 0.567 in girls) and the positive predictive value ( 0.163 in boys and 0.121 in girls) were considerably reduced compared to the other cut-offs.

\section{Discussion}

This study shows very good agreement of the simple fixed cut-off of 0.5 for the WHtR compared to the age- and sex-specific $\mathrm{P} 90$ with respect to prevalence rates for abdominal obesity and diagnostic quality of WHtR and BMI in a representative sample of adolescents in Germany. The strengths of our study are the large, nationally representative sample, standardized measurements, and up-to-date statistical methods for percentile derivation. Due to the use of the WHtR cut-off of 0.5 , prevalence rates for abdominal obesity are internationally comparable. The KiGGS data on WHtR can be used as baseline data for long-term observation of abdominal obesity trends among German adolescents. In our study a very good agreement was found when using the cut-off 0.5 and the age- and sex-specific P90 to assess abdominal obesity. In populations with lower or higher WHtR values, the prevalence rates may be different when using these two cut-points.

Despite the suggestion to use the WHtR cut-off of 0.5 in children and adolescents [4, 5], comparable prevalence values given for other studies are scarce. Using this definition, Li et al. [10] reported prevalence rates for abdominal obesity of $28.8 \%$ for male and $36.4 \%$ for female adolescents from the USA aged 12-17 years for the time period 1999-2004. They found lower prevalence rates in the National Health and Nutrition Examination Survey III for the time period $1988-1994$ with $18.7 \%$ for boys and $24.2 \%$ for girls. In contrast, only $5 \%$ of 15-year-old Swedish boys from the European Youth Heart Study (girls 4\%) were abdominally obese in 1998-1999 [24]. In this study, the number of subjects with abdominal obesity was higher than that with overall obesity assessed by BMI in both sexes. This finding is consistent with our observation, although the prevalence rates of abdominal obesity were markedly higher in German adolescents in 2003-2006. The high rates of abdominal obesity in our subjects refer to high visceral fat mass, which is assumed to be one of the key players in the development of metabolic consequences of obesity. The differences in the prevalence rates between the above mentioned studies may not only reflect differences in the degree of body fatness between the study populations, but also different techniques for WC measurements. While WC has been measured most commonly at the narrowest part of the trunk, in the Third National Health and Nutrition Examination Survey it was measured right above the iliac crest [25]. This technique may lead to higher values for WC and therefore to higher prevalence rates.

Our results show a good agreement between BMI as well as WHtR and BP measures. Both anthropometric parameters were positively correlated with BP and differed only slightly in their ability to identify adolescents with hypertensive BP values. Both indices presented 
larger AUC for systolic BP than for diastolic BP in both sexes. This stronger relationship of the WHtR to the systolic BP than to the diastolic BP is consistent with other studies [26-28].

Despite the association between WHtR and BP, the ability of both WHtR cut-off points to detect subjects with hypertensive BP values was modest in our study, with low sensitivities around 20-30\%. Moreover, detection of hypertensive BP appears to be modest across the whole range of possible WHtR cut-offs, as shown by the AUC statistics. We could improve the predictive ability by selecting WHtR cut-offs for hypertensive BP values with the best tradeoff between sensitivity and specificity. These cut-off values of 0.43 in boys and 0.42 in girls were near the 50th percentile values and provide evidence for the development of hypertensive BP in subjects with lower WHtR. Although the sensitivity of these obtained cut-off points is higher compared to that of the others $(\mathrm{P} 90,0.5)$, it still reaches only approximately $60 \%$. Our results suggest that BMI has similar limitations as a screening parameter for hypertensive BP and its sensitivity when using the IOTF definition is even lower than that of the two WHtR cut-offs. A previous analysis with KiGGS data showed generally similar, but overall moderate diagnostic ability of various anthropometric indices including WHtR P90 and BMI to detect other cardiovascular risk factors [29]. Findings in studies in children and adolescents comparing the performance of WHtR and BMI were controversial. Some studies found that WHtR correlates more strongly with CVD risk factors than does BMI [26, 30, 31], others reported differences concerning the investigated risk factors [32] or have not found any difference in the ability of WHtR and BMI or BMI-for-age to predict CVD risk [29, 33-35]. The concordance of BMI and WHtR in their predictive ability could be attributed to the high correlation between total body fat and abdominal body fat [36] or to the relatively low intraabdominal fat mass of children and adolescents [37]. In this context, investigating sensitivity and specificity of WHtR to identify other CVD risk factors (e. g. lipid status) would be an interesting aim for a further study.

Although it is difficult to compare the magnitude of the observed associations due to methodological differences between the studies, e.g. the use of BMI or BMI-for-age, age ranges, examined risk factor, and differences concerning the measurement of $\mathrm{WC}$, the majority of these studies reported only a moderate ability of BMI or BMI-for-age and WHtR to discriminate subjects with and without hypertensive BP values or other CVD risk factors.

These findings indicate that the WHtR, just as other measures of obesity, should not be used to screen adolescents for increased BP but that measurements of BP are required in all adolescents. This is especially important because hypertensive BP among adolescents is often unrecognized, underdiagnosed, and hence unmanaged [38].

However, the association of WHtR with metabolic outcomes, as found in our study as well as in other studies, suggests this index with other proxies for obesity, namely BMI, as a risk indicator in adolescents. Because there is considerable evidence that accumulation of abdominal fat during adolescence increases the risk for metabolic complications in adulthood [39], WHtR would be a good screening tool for abdominal obesity, probably better than BMI. Furthermore, because there is no or at the utmost low age dependency in the WHtR as shown in our as well as in other studies [40-42], a fixed cut-point can be used to define abdominal obesity; it is not necessary to express measures as percentiles or Z-scores as is the case for BMI. In addition, we found that the use of either adjusted or unadjusted measures of WHtR (correlation between unadjusted and age-adjusted measures of WHtR was 0.988 and 0.998 in boys and girls, respectively) yielded almost identical results. The unique and compelling simplicity of the message 'keep your waist to half your height', which refers to a WHtR of 0.5 , singles out the WHtR as particularly attractive for prevention purposes, and our analyses indicate that it is generally similar to a more cumbersome percentile-based cut-off.

A possible limitation of our study is the use of the definition of obesity based on IOTF criteria. The review of Reilly et al. [43] provides evidence that supports the use of national 
Kromeyer-Hauschild et al.: Abdominal Obesity in German Adolescents Defined by

reference data to define childhood obesity for clinical applications. Using the German BMI reference data [44] to define obesity in our study led to slightly higher prevalence rates in boys $(7.7 \%)$ and significantly higher rates in girls (8.3\%) compared to those derived from the IOTF criteria. Because there were not any notable differences in the association with BP using the German reference (data no shown), we decided to use the IOTF reference to enable international comparisons.

In summary, this study provides prevalence rates for abdominal obesity based on the WHtR in German adolescents and shows that the fixed cut-off of 0.5 and the P90 cut-off yield similar results. In addition, the WHtR as well as BMI had unsatisfactory abilities to discriminate hypertensive BP and therefore do not appear suitable as screening tools for hypertensive BP in adolescents. However, the significant relationship of WHtR and BMI to BP suggest these indices as risk indicators in adolescents. Because BMI requires the use of a cumbersome percentile chart with age- and sex-dependent cut-offs, WHtR with the constant cut-off of 0.5 could be the better choice for many settings. The simple massage 'keep your waist circumference to less than half your weight' may be especially useful in clinical and public health settings and allows one to obtain comparable prevalence rates for abdominal obesity at the global level. However, in all settings care must be taken concerning the measurements of the WC. Clothing during the measurements as well as the site of measurement needed to be standardized.

Forthcoming follow-up measurements in KiGGS participants will provide longitudinal data on the tracking of WHtR from adolescents to adulthood and data relating WHtR to metabolic and cardiovascular outcomes to validate the fixed 0.5 cut-off of WHtR.

\section{Acknowledgements}

The KiGGS survey was funded by the German Ministry of Health, the Ministry of Education and Research, and the Robert Koch Institute.

\section{Disclosure Statement}

No conflict of interest is declared.

\section{References}

1 Ashwell M, Gunn P, Gibson S: Waist-to-height ratio is a better screening tool than waist circumference and BMI for adult cardiometabolic risk factors: systematic review and meta-analysis. Obes Rev 2012;13:275-286.

-2 Gruson E, Montaye M, Kee F, Wagner A, Bingham A, Ruidavets JB, Haas B, Evans A, Ferrieres J, Ducimetiere PP, Amouyel P, Dallongeville J: Anthropometric assessment of abdominal obesity and coronary heart disease risk in men: the PRIME study. Heart 2010;96:136-140.

-3 Lee CM, Huxley RR, Wildman RP, Woodward M: Indices of abdominal obesity are better discriminators of cardiovascular risk factors than BMI: a meta-analysis. J Clin Epidemiol 2008;61:646-653.

4 Ashwell M, Hsieh SD: Six reasons why the waist-to-height ratio is a rapid and effective global indicator for health risks of obesity and how its use could simplify the international public health message on obesity. Int J Food Sci Nutr 2005;56:303-307.

5 McCarthy HD, Ashwell M: A study of central fatness using waist-to-height ratios in UK children and adolescents over two decades supports the simple message - 'keep your waist circumference to less than half your height'. Int J Obes (Lond) 2006;30:988-992.

6 Hsieh SD, Yoshinaga H: Abdominal fat distribution and coronary heart disease risk factors in men-waist/ height ratio as a simple and useful predictor. Int J Obes Relat Metab Disord 1995;19:585-589.

7 Hsieh SD, Yoshinaga H, Muto T: Waist-to-height ratio, a simple and practical index for assessing central fat distribution and metabolic risk in Japanese men and women. Int J Obes Relat Metab Disord 2003;27:610-616. 
Kromeyer-Hauschild et al.: Abdominal Obesity in German Adolescents Defined by

8 Browning LM, Hsieh SD, Ashwell M: A systematic review of waist-to-height ratio as a screening tool for the prediction of cardiovascular disease and diabetes: 0.5 could be a suitable global boundary value. Nutr Res Rev 2010;23:247-269.

-9 Roswall J, Bergman S, Almqvist-Tangen G, Alm B, Niklasson A, Nierop AF, Dahlgren J: Population-based waist circumference and waist-to-height ratio reference values in preschool children. Acta Paediatr 2009;98:16321636.

10 Li C, Ford ES, Mokdad AH, Cook S: Recent trends in waist circumference and waist-height ratio among US children and adolescents. Pediatrics 2006;118:e1390-e1398.

-11 Motswagole BS, Kruger HS, Faber M, van Rooyen JM, de Ridder JH: The sensitivity of waist-to-height ratio in identifying children with high blood pressure. Cardiovasc J Afr 2011;22:208-211.

-12 Fujita Y, Kouda K, Nakamura H, Iki M: Cut-off values of body mass index, waist circumference, and waist-toheight ratio to identify excess abdominal fat: population-based screening of Japanese school children. J Epidemiol 2011;21:191-196.

-13 Kurth BM, Kamtsiuris P, Holling H, Schlaud M, Dolle R, Ellert U, Kahl H, Knopf H, Lange M, Mensink GB, Neuhauser H, Rosario AS, Scheidt-Nave C, Schenk L, Schlack R, Stolzenberg H, Thamm M, Thierfelder W, Wolf $\mathrm{U}$ : The challenge of comprehensively mapping children's health in a nation-wide health survey: design of the German KiGGS-Study. BMC Public Health 2008;8:196.

14 Kromeyer-Hauschild K, Dortschy R, Stolzenberg H, Neuhauser H, Rosario AS: Nationally representative waist circumference percentiles in German adolescents aged 11.0-18.0 years. Int J Pediatr Obes 2011;6:e129-e137.

15 Lohman TG, Roche AF, Martorell R: Anthropometric Standardization Reference Manual. Champaign, Human Kinetics, 1988.

16 Neuhauser HK, Schienkiewitz A, Schaffrath Rosario A, Dortschy R, Kurth BM: Referenzperzentile für anthropometrische Maßzahlen und Blutdruck aus der Studie zur Gesundheit von Kindern und Jugendlichen in Deutschland (KiGGS) 2003-2006. Beiträge zur Gesundheitsberichterstattung des Bundes. Berlin, Robert Koch-Institut, 2011.

17 Cole TJ, Bellizzi MC, Flegal KM, Dietz WH: Establishing a standard definition for child overweight and obesity worldwide: international survey. BMJ 2000;320:1240-1243.

18 Cole TJ, Green PJ: Smoothing reference centile curves: the LMS method and penalized likelihood. Stat Med 1992;11:1305-1319.

19 Chobanian AV, Bakris GL, Black HR, Cushman WC, Green LA, Izzo JL, Jones DW, Materson BJ, Oparil S, Wright JT, Roccella EJ: The seventh report of the Joint National Committee on Prevention, Detection, Evaluation, and Treatment of High Blood Pressure - the JNC 7 Report. JAMA 2003;289:2560-2572.

20 Neuhauser HK, Thamm M, Ellert U, Hense HW, Rosario AS: Blood pressure percentiles by age and height from nonoverweight children and adolescents in Germany. Pediatrics 2011;127:e978-e988.

-21 Rosario AS, Schienkiewitz A, Neuhauser H: German height references for children aged 0 to under 18 years compared to WHO and CDC growth charts. Ann Hum Biol 2011;38:121-130.

22 Rosario AS, Kurth BM, Stolzenberg H, Ellert U, Neuhauser H: Body mass index percentiles for children and adolescents in Germany based on a nationally representative sample (KiGGS 2003-2006). Eur J Clin Nutr 2010;64:341-349.

23 Landis JR, Koch GG: The measurement of observer agreement for categorical data. Biometrics 1977;33:159174.

24 Ortega FB, Ruiz JR, Vicente-Rodriguez G, Sjostrom M: Central adiposity in 9- and 15-year-old Swedish children from the European Youth Heart Study. Int J Pediatr Obes 2008;3:212-216.

25 National Center for Health Statistics. The Third National Health and Nutrition Examination Survey, 19881994. Plan and Operations Procedures Manuals. Hyattsville, Centers for Disease Control and Prevention, 1996.

26 Hara M, Saitou E, Iwata F, Okada T, Harada K: Waist-to-height ratio is the best predictor of cardiovascular disease risk factors in Japanese schoolchildren. J Atheroscler Thromb 2002;9:127-132.

27 Mirzaei M, Taylor R, Morrell S, Leeder SR: Predictors of blood pressure in a cohort of school-aged children. Eur J Cardiovasc Prev Rehabil 2007;14:624-629.

28 Sung RY, Yu CC, Choi KC, McManus A, Li AM, Xu SL, Chan D, Lo AF, Chan JC, Fok TF: Waist circumference and body mass index in Chinese children: cutoff values for predicting cardiovascular risk factors. Int J Obes (Lond) 2007;31:550-558.

-29 Kleiser C, Schienkiewitz A, Schaffrath RA, Prinz-Langenohl R, Scheidt-Nave C, Mensink GB: Indicators of overweight and cardiovascular disease risk factors among 11- to 17-year-old boys and girls in Germany. Obes Facts 2011;4:379-385.

-30 Savva SC, Tornaritis M, Savva ME, Kourides Y, Panagi A, Silikiotou N, Georgiou C, Kafatos A: Waist circumference and waist-to-height ratio are better predictors of cardiovascular disease risk factors in children than body mass index. Int J Obes Relat Metab Disord 2000;24:1453-1458.

-31 Kahn HS, Imperatore G, Cheng YJ: A population-based comparison of BMI percentiles and waist-to-height ratio for identifying cardiovascular risk in youth. J Pediatr 2005;146:482-488.

-32 Ribeiro RC, Coutinho M, Bramorski MA, Giuliano IC, Pavan J: Association of the waist-to-height ratio with cardiovascular risk factors in children and adolescents: the Three Cities Heart Study. Int J Prev Med 2010;1: 39-49.

33 Maximova K, Chiolero A, O'Loughliin J, Tremblay A, Lambert M, Paradis G: Ability of different adiposity indicators to identify children with elevated blood pressure. J Hypertens 2011;29:2075-2083. 
Kromeyer-Hauschild et al.: Abdominal Obesity in German Adolescents Defined by

-34 Freedman DS, Kahn HS, Mei Z, Grummer-Strawn LM, Dietz WH, Srinivasan SR, Berenson GS: Relation of body mass index and waist-to-height ratio to cardiovascular disease risk factors in children and adolescents: the Bogalusa Heart Study. Am J Clin Nutr 2007;86:33-40.

-35 Campagnolo PD, Hoffman DJ, Vitolo MR: Waist-to-height ratio as a screening tool for children with risk factors for cardiovascular disease. Ann Hum Biol 2011;38:265-270.

-36 Huang TT, Johnson MS, Figueroa-Colon R, Dwyer JH, Goran MI: Growth of visceral fat, subcutaneous abdominal fat, and total body fat in children. Obes Res 2001;9:283-289.

-37 Goran MI, Kaskoun M, Shuman WP: Intra-abdominal adipose tissue in young children. Int J Obes Relat Metab Disord 1995;19:279-283.

38 Hansen ML, Gunn PW, Kaelber DC: Underdiagnosis of hypertension in children and adolescents. JAMA 2007; 298:874-879.

39 Cameron N, Jones LL, Griffiths PL, Norris SA, Pettifor JM: How well do waist circumference and body mass index reflect body composition in pre-pubertal children? Eur J Clin Nutr 2009;63:1065-1070.

40 Aeberli I, Gut-Knabenhans M, Kusche-Ammann RS, Molinari L, Zimmermann MB: Waist circumference and waist-to-height ratio percentiles in a nationally representative sample of 6-13 year old children in Switzerland. Swiss Med Wkly 2011;141:w13227.

-41 Kahn HS, Imperatore G, Cheng YJ: A population-based comparison of BMI percentiles and waist-to-height ratio for identifying cardiovascular risk in youth. J Pediatr 2005;146:482-488.

42 Weili Y, He B, Yao H, Dai J, Cui J, Ge D, Zheng Y, Li L, Guo Y, Xiao K, Fu X, Ma D: Waist-to-height ratio is an accurate and easier index for evaluating obesity in children and adolescents. Obesity (Silver Spring) 2007;15:748-752.

43 Reilly JJ, Kelly J, Wilson DC: Accuracy of simple clinical and epidemiological definitions of childhood obesity: systematic review and evidence appraisal. Obes Rev 2010;11:645-655.

44 Kromeyer-Hauschild K, Wabitsch M, Kunze D, Geller D, Geiss HC, Hesse V, von Hippel A, Jaeger U, Johnsen D, Korte W, Menner K, Muller G, Muller JM, Niemann-Pilatus A, Remer T, Schaefer F, Wittchen HU, Zabransky S, Zellner K, Ziegler A, Hebebrand J: Percentiles of body mass index in children and adolescents evaluated from different regional German studies. Monatsschr Kinderheilkd 2001;149:807-818. 